\title{
A case of mistaken identity: HSPs are no DAMPs but DAMPERs
}

\author{
Willem van Eden • Rachel Spiering • Femke Broere • \\ Ruurd van der Zee
}

Received: 9 November 2011 / Accepted: 15 November 2011 /Published online: 3 December 2011

(C) The Author(s) 2011. This article is published with open access at Springerlink.com

\begin{abstract}
Until recently, the immune system was seen solely as a defense system with its primary task being the elimination of unwanted microbial invaders. Currently, however, the functional significance of the immune system has obtained a much wider perspective, to include among others the maintenance and restoration of homeostasis following tissue damage. In this latter aspect, there is a growing interest in the identification of molecules involved, such as the so-called danger or damage-associated molecular patterns (DAMPs), also called alarmins. Since heat shock proteins are archetypical molecules produced under stressful conditions, such as tissue damage or inflammation, they are frequently mentioned as prime examples of DAMPs (Bianchi, J Leukoc Biol 81:1-5, 2007; Kono and Rock, Nat Rev Immunol 8:279-289, 2008; Martin-Murphy et al., Toxicol Lett 192:387-394, 2010). See for instance also a recent review (Chen and Nunez, Science 298:13951401, 2010). Contrary to this description, we recently presented some of the arguments against a role of heat shock protein as DAMPs (Broere et al., Nat Rev Immunol 11:565-c1, 2011). With this perspective and reflection article, we hope to elaborate on this debate and provide additional thoughts to further ignite this discussion on this critical and evolving issue.
\end{abstract}

Keywords DAMP · HSP · Treg · Inflammation · HSP70 . Danger $\cdot$ Arthritis $\cdot$ Peptides $\cdot$ Autoimmunity

\footnotetext{
W. van Eden $(\varangle) \cdot R$. Spiering $\cdot$ F. Broere $\cdot R$. van der Zee Department of Infectious Diseases and Immunology, Faculty of Veterinary Medicine, Utrecht University, Yalelaan 1, $3584 \mathrm{CL}$, Utrecht, Netherlands e-mail: w.vaneden@uu.nl
}

\section{What are DAMPs?}

In the 1990s, Polly Matzinger introduced the concept of immunological "danger" as a further refinement of Burnet's original clonal selection theory which is the basis of self-nonself discrimination by the immune system (Fuchs and Matzinger 1996). In her "danger" concept of immune function, she proposed immune responses result from detecting and addressing danger and not just nonself. In this context, the molecules associated with distress and damage (including self molecules) are regarded as the prime stimuli for immunological reactivity.

Self-danger signals were postulated to originate from, for instance, necrotic cells that succumb to infection or ischemia. Subsequently, several molecules were ascribed "danger"-associated molecule (DAMPs) functions, such as high-mobility group box-1 (HMGB1) protein, the most abundant member of the HMG family of DNA-binding proteins. Other candidates include cytosolic calciumbinding proteins of the S-100 family, nucleosomes, uric acid, and antibacterial peptides (Harris and Raucci 2006). It was logical and attractive to incorporate into this concept families of heat shock proteins (HSPs) as they are upregulated during stressful cellular events such as in tissue necrosis. HSPs have since often been categorized as prototypic "danger" associated molecular patterns or DAMPs.

As a brief aside, the terminology in this field exemplifies the continuing maturation of the danger concept since its original inception. The term DAMPs is given in analogy with the earlier coined PAMPs (pathogenassociated molecular patterns), which were proposed to be structures recognized by so-called pattern recognition recep- 
tors. At this moment, however, DAMPs is more known as "damage"-associated molecular patterns. The latter was proposed for the situation in clinical organ transplantation, where the transplant does not reflect a danger but rather a benefit to the recipient. The upregulated HSPs resulting from reperfusion injury were therefore viewed as a typical DAMP in the sense of "damage" and not danger-associated molecular pattern (Land 2005).

In the more narrow definition, DAMPs are intracellular nonmicrobial molecules normally hidden from recognition by the immune system. They are released during necrotic and not apoptotic cell death, after which the innate immune system responds both directly with inflammation and indirectly by recruiting reinforcements from the adaptive immune system (Kono and Rock 2008). Kono and Rock have attempted to outline four criteria in terms of biological outcomes that must be fulfilled for a molecule to be classified as a DAMP (Kono and Rock 2008):

1. A DAMP should be active as a highly purified molecule

2. The biological effect should not be owing to contamination with microbial molecules. Caution is particularly warranted if the putative DAMP is found to work through receptors for PAMPs such as toll-like receptors (TLRs).

3. The DAMP should be active at concentrations present in pathophysiological situations

4. Selective elimination or inactivation of the DAMP should ideally inhibit the biological activity of dead cells in in vitro or in vivo assays.

In the case of HSPs, the first two criteria are already problematic. Given their chaperone nature, HSPs readily engage other molecular structures, and experience has taught us that recombinant HSPs are easily contaminated with microbial products when produced in microbial expression systems. Criterion 4, by the authors' own admission, is an ideal effect, and in most cases, this criterion is not fulfilled. To put it bluntly, it seems questionable whether or not there exists any single DAMP which meets all of these criteria. Our brief analysis of the current literature on DAMPs suggested that convincing evidence for single DAMP molecules initiating proinflammatory responses, as proven by the above criteria, may be lacking so far.

Microbial HSPs are immunodominant and induce cross-reactivity with self-HSP

One of the remarkable characteristics of HSPs is their immunodominance. HSP60 was already known as the "common antigen" of gram-negative bacteria before the actual recognition of its molecular identity. Immunization with gram-negative bacteria led to the production of high levels of antibodies specific for this common antigen (Thole et al. 1988). Since the mycobacterial HSP60 molecule was cloned (Thole et al. 1985), Kaufmann and others have performed immunization studies with mycobacteria and with recombinant mycobacterial HSP60 demonstrating the resulting frequency of HSP60-specific $\mathrm{T}$ cells can be very high. After immunization with Mycobacterium tuberculosis, approximately one out of five of the M. tuberculosis-reactive T cells recognizes HSP60. Immunization with recombinant HSP60 in an adjuvant also stimulated an impressively high number of M. tuberculosisreactive $\mathrm{T}$ cells (1 out of 2,000) (Kaufmann et al. 1987). Since then, many others have shown the dominant immunogenicity of microbial HSPs (Zugel and Kaufmann 1999).

Given the conserved nature of HSPs, this high level of immunogenicity is not immediately understood. One would predict a low degree of immunogenicity for molecules having extensive sequence similarities with self antigens. A healthy immune system is not supposed to respond to self antigens or their closely related homologs. Paradoxically, when mapping T cell epitopes for mycobacterial HSP60 in Lewis rats, defined epitopes included many conserved sequences, and the responding T cells were found to crossrespond to homologous self-peptide derived from mammalian HSP60 (Anderton et al. 1995). Since then, self-HSP crossreactive $\mathrm{T}$ cells have been identified in many models and even in human cord blood (Durai et al. 2004; Paul et al. 2000). In children suffering from juvenile idiopathic arthritis, their strongest $\mathrm{T}$ cell responses to self-HSP60 were detected in patients during remitting phases of their disease, suggestive of an anti-inflammatory mechanism resulting from selfHSP-directed T cell reactivity (de Graeff-Meeder et al. 1995; de Kleer et al. 2003; Prakken et al. 1996).

Furthermore, autoantibodies against HSP have been found to be prevalent in healthy subjects. For HSP60, this was summarized by Quintana and Cohen (2011). Similar patterns of autoantibodies are observed for self-HSP70, for example in diabetes and atherosclerosis (AbulafiaLapid et al. 2003). Interestingly, antigen microarray analysis for multiple sclerosis (MS) patients revealed that HSP70 autoantibodies were a characteristic antibody signature of patients with a remitting and relapsing form of the disease. These antibodies were much less abundant in patients with progressive forms of MS, again associating HSP70 immune reactivity with disease remission (Quintana et al. 2008).

The immunodominance of HSPs may not depend on interactions with innate receptors

There are no reports of peculiar pro-inflammatory isotype (e.g., IgG2a) profiles for HSP-binding antibodies in patients 
with autoimmune diseases. And as an aside, direct polyclonal stimulation of mouse B cells with human HSP60 induced production of IgG3. These activated B cells were also found to stimulate a Th0 profile in T cells as opposed to a typical Th1, as indicated by their production of interleukin (IL)-10 and interferon gamma (INF- $\gamma$; Cohen-Sfady et al. 2005). In addition, T cells reactive to HSPs that have been reported were typically not proinflammatory, regardless of whether they were stimulated with mammalian (self) HSP or microbial HSPs. In stark contrast, many antibodies or responding T cells were found to have anti-inflammatory activities (Moudgil et al. 1997; Ulmansky et al. 2002; van Eden et al. 2005). These were demonstrated by their abilities to suppress an inflammatory disease or to produce anti-inflammatory cytokines such as IL-10 (Prakken et al. 2001). In other words, despite the fact that responses to HSPs may be of fundamental interest to the immune system, the phenotypic characteristic of HSP immune reactivity does not reflect a typical DAMPassociated pro-inflammatory response.

Be that as it may, one cannot exclude that the dominant immunogenicity of HSP stems from their interaction with TLRs or other innate receptors. However, there remain other possibilities which may explain the potent immunogenicity of HSPs equally well (Table 1). Firstly, the more practical explanation is exposure. The immune system is in continuous contact with conserved microbial HSPs. The symbiotic relationship between the gut and intestinal microbiota ensures the regular immunological surveillance of our resident flora. Be it benign colonization by commensals or true invasion by pathogens, it will impose stress on every intruder, which will lead to an upregulation of microbial HSP and provide ample and repetitive opportunity for our immune system to respond to HSP. And logically, the immune response would most frequently encounter the most conserved epitopes. In this response, the expansion of $\mathrm{T}$ cells specific for conserved epitopes increases the likelihood of cross-reactivity with self-HSP. Secondly, given their chaperone activities, an alternative explanation is that HSPs are hitchhiking with other antigens for uptake and processing by antigen-presenting cells. In this manner, they may frequent the priority lane in the antigen processing system. A third possibility is that HSPs have an organized priority status for the immune system. Cohen has argued that HSPs are examples of immune-

Table 1 Mechanisms leading to the HSP immunodominance

Repeated contact leads to a focus on conserved regions Hitchhiking in the antigen uptake and processing machinery Built-in feature of the immune system (homunculus idea) Triggering of innate TLR receptors? privileged antigens, so-called homunculus antigens. This would imply that the reactivity to such molecules is a genetically determined inherent quality of the immune system (Cohen 2007). Thus, there are more ways to explain the exceptional immunogenicity of HSP, which do not depend on immediate interaction with TLRs or other receptors of the innate immune system. In conclusion, although the high immunogenicity may suggest innate receptors to be involved, there are ample alternative options to explain this aspect of HSP.

A primary feature of chaperones is their capacity to bind peptides. HSP70 has peptide-binding domains for exposed hydrophobic residues of substrate proteins. When peptideloaded HSP70 is delivered to dendritic cells (DCs), the peptide is rerouted through the major histocompatibility complex (MHC) class I pathway antigen presentation, via cross-presentation, for display to $\mathrm{CD} 8^{+}$cytotoxic $\mathrm{T}$ cells (Rock and Shen 2005). In a number of studies on crosspresentation by HSP, evidence was provided for a stimulatory effect on DC maturation and activation (Binder 2009). With respect to accompanying DC maturation, controversy has arisen regarding the role of microbial contaminants in this DC stimulatory effect as some authors have presented evidence that lipopolysaccharide (LPS; TLR4), lipoprotein (TLR2), or flagellin (TLR5) were the active compounds here (Tsan and Gao 2009). In one study, purposeful removal of contaminating LPS did not prevent peptide presentation, but did abrogate activation of human DCs in association with human HSP70 (Bausinger et al. 2002). In juxtaposition, peptides fused to HSP60 also induced CD8 ${ }^{+}$ cytotoxic T cells (Cho et al. 2000). This fusion product was stimulatory to DCs, leading to upregulation of MHC (class I and II) and co-stimulatory molecules (B7.2), whereas unexpectedly HSP60 alone was not stimulatory. Again, this led to a suspected role of contaminants in the fusion proteins. Thus, although cross-presentation mediated by HSP seems real, the DC stimulating activities may be uncertain, to say the least. A balanced review which, overall, argues against endotoxin being the "active" ingredient in many HSP effects is however Henderson et al. (2010).

The difficulty of the "one molecule-one receptor-one functional response" idea

DAMPs are generally regarded as being intracellular proteins that are hidden from recognition by the immune system until exposed by cell damage, such as necrosis. Presumably, this release of DAMPs into the extracellular fluid begins an inflammatory response. Several receptors are purported to mediate DAMP recognition (e.g., receptor for advanced glycation end products (RAGE) and TLR9) and subsequently propagate an inflammatory response. 
Additionally, the supposed danger qualities of HSP are proposed to be mediated through receptor-mediated endocytosis (Arnold-Schild et al. 1999). In the latter case TLRs, such as TLR2 and 4, are again implicated as the dominating receptors (Vabulas et al. 2001).

There is now a general consensus that the interactions of TLRs with PAMPs evolved to prepare the immune system for tailor-made responses to invading microbes. A diversity of TLRs (and also RIGS, NOD, etc.) enables the immune system to be discriminative at the early level of innate defenses. A microbe that activates TLR4 and TLR5 is likely to be a flagellated gram-negative bacterium, while a microbe that triggers TLR2, 5 , and 6 qualifies to be a flagellated grampositive bacterium. Very aptly, this was called the barcode model of immune recognition (Aderem 2003). However, this concept raises several questions with regard to HSPs. Which advantageous aspect would HSPs serving as DAMPs offer to this system? What would have been the evolutionary advantage of having HSP as a DAMP included in such a recognition strategy? A direct innate response to proteins released by necrotic cells, unidirectionally activating a proinflammatory response, would disturb the "bar coding" mediated through TLR and other innate receptors. A feature of TLRs which still remains to be fully appreciated is that they generate not only pro-inflammatory responses but also suppressive responses in innate immune cells (Conroy et al. 2008). TLR2 for example has been shown to be present on Treg cells, and its triggering by an HSP60-derived peptide led to cytokine and contact-dependent suppression (Zanin-Zhorov et al. 2006). Also, TLR2 triggering by Pam3Cys led to Treg induction (Sutmuller et al. 2006). In addition, IL-10-producing $\mathrm{T}$ cells were generated in vivo through TLR2 triggering by capsular polysaccharides of commensal bacteria (Round and Mazmanian 2010). TLR4 triggering by LPS was seen to enhance survival and proliferation of Treg cells (Caramalho et al. 2003). This means that these receptors have no danger conveying power on their own. The effect of their triggering is therefore most likely cell-type specific and may depend very much on the context of their triggering, other factors released by other cells in the vicinity, and other receptors triggered simultaneously. In other words, the integration of multiple signals must finally converge within a particular cell to drive the biological outcome. Given the examples of suppressive effects by HSP-derived peptides in this context, it seems even possible that HSPs are dampening inflammatory signals through these innate receptors.

The search for dedicated heat shock protein receptors has been intensive over the past years. We are left with a broad array of receptors with rather promiscuous binding characteristics. Of the scavenger receptors, heat shock proteins are now known to interact with SRA-1, SREC-1, LOX-1, and FEEL-1 (Calderwood et al. 2007). Interestingly, some of these receptors were found to be immunosuppressive, such as SRA-1 (Wang et al. 2007). As put forth by Calderwood: "Discerning the signaling networks emanating from such an array of receptors will be challenging; however, this is essential if sense is to be made of the heat shock protein signal input" (reported in (Henderson et al. 2010). Whatever the outcome of such an exploration will be, a simply straightforward monotonous pro-inflammatory HSP response will be an unlikely outcome. It is the result of modern cellular and molecular technologies that we tend to study single types of cells in their interactions with single defined molecules through tentative single receptors. However, in reality, the complexity of immune behavior will not be visible by analyzing a linear sequence of consecutive events from cause to effect. We will need a systems biology approach to integrate responses to HSP into a context-dependent unified systemic response.

\section{DAMP disqualifying features of HSP}

A variety of molecules have been nominated to trigger innate receptors in a pro-inflammatory manner. They are often presented as putative DAMPs, despite the fact there may be no discernable patterns associated with their molecular structures. However, this is generally accepted as the name DAMP was coined in keeping with the PAMPs analogy of which the classical examples exhibit obvious molecular patterns. Yet, HSPs are not known to harbor any molecular patterns or to have any sequence or structural similarities between HSP of different families. Possibly with an exception, if we accept the suggestion of hydrophobicity as a damage-associated molecular pattern. In that case, HSP may have hydrophobic binding sites that are exposed in an ATPdependent manner to allow binding to hydrophobic parts of nascent or unfolded proteins (Seong and Matzinger 2004). Possibly of more relevance to our discussion is the fact that there are no systematic differences between self and microbial HSP. Therefore, the immune system does not seem to possess receptors that may distinguish the self from microbial. As a consequence, if self-HSPs were DAMPs, one would also expect the immunodominant microbial HSPs to exert a continuous pro-inflammatory effect in our immune system: an unlikely and not very attractive situation.

DAMPs typically reside intracellularly and are only exposed to the extracellular environment when cells undergo necrosis. However, HSPs are also exposed at the cell surface (Multhoff 2007) and exist as freely circulating HSP (Pockley and Multhoff 2008), and neither of these forms are easily compatible with DAMP-type proinflammatory activities of HSP.

Some DAMPs are claimed to exert their effects via a receptor associated with pro-inflammatory signaling. This is the case given for HMBG-1 and RAGE. Antibody blocking of RAGE was seen to inhibit the ability of 
HMGB-1 to promote inflammation and was taken as proof that RAGE binds a pro-inflammatory HMBG-1 (Luan et al. 2010). However, despite the fact that HMBG-1 may be taken as a prototypic DAMP, its role in directly promoting inflammation is also clouded in controversy (Bianchi 2007). In fact, the discussions here are similar to those concerning HSPs as HMBG-1 can also complex with other molecules such as LPS, and these associations are incriminated as the possible sources of the pro-inflammatory stimuli. Highly purified recombinant HMGB-1 was demonstrated to have a very weak direct pro-inflammatory activity at best (Rouhiainen et al. 2007). To quote another paper: "Thus, for full activity, HMGB1 may need to form a complex with another component to activate inflammation by enhancing effects stimulated by a PAMP, a DAMP, or a proinflammatory cytokine. Importantly, HMGB1 can bind avidly to immuno-stimulatory molecules such as LPS, DNA, or interleukin (IL)-1 $\beta$ and promote their activity in a synergistic fashion" (Pisetsky et al. 2008).

As mentioned, no specific or unique receptors are known for HSPs. And the most credited TLR receptors are not strictly pro-inflammatory. Interestingly, TLR2 and TLR4, which are possibly the primary receptors for HSP60 and HSP70, were found not to be essential in the host response to DAMPs derived from necrotic cells (Chen and Nunez 2010). Most relevant in this discussion are the results of experiments in which DCs were cultured in the presence of HSPs. For self-HSP, there is a lack of compelling evidence that HSP can directly activate dendritic cells, which are expected to express the whole panoply of DAMP receptors. When exorbitant concentrations $(200-300 \mu \mathrm{g} / \mathrm{ml})$ of selfHSP70 (purified from mouse liver using standard protocols under sterile conditions and with endotoxin-free reagents) were applied, no stimulatory effects on murine DCs were observed (Wallin et al. 2002). As an aside, the same authors have seen responses to low concentrations $(50-100 \mathrm{ng} / \mathrm{ml})$ of the same liver-derived HSP70 contaminated with minute amounts of endotoxin. Given the role of dendritic cells as key initiators of the immune response and their ability to give direction to the ensuing adaptive response, one may wish to see full activation of DCs for a pro-inflammatory adaptive immune response reaction. In even more careful analyses, human HSP70 has shown a lack of direct human DC activation qualities (Bendz et al. 2008). Despite earlier claims (Floto et al. 2006), even mycobacterial HSP70 exhibited an absence of activation (no calcium signaling) of human DCs (Bendz et al. 2008). And possibly more telling, the group of Bonorino has shown that highly purified mycobacterial HSP70 impaired the maturation of murine bone marrow-derived DCs, leading to inhibition of T cell proliferation (Motta et al. 2007). Finally, HSPs seem to exert immune-dampening effects in model systems, as we will discuss in the following section (Table 2).
Table 2 Features of HSPs which disqualify them as DAMPs

Absence of molecular patterns

Main receptors TLR2 and TLR4 are not always pro-inflammatory

TLR2 and TLR4 are not needed for signaling by DAMPs from necrotic cells

Some HSP receptors are downregulating inflammatory signaling

HSP-incubated DCs adopt a tolerogenic phenotype

HSP immunizations are anti-inflammatory

The immune-"dampening" activity of HSP

Initial studies of the immunological effect of HSP were carried out with recombinant mycobacterial HSP60 in the rat model of adjuvant arthritis. HSP60 immunizations were found to inhibit disease development in this T cell-mediated autoimmune disease model (van Eden et al. 1988). This disease ameliorative effect was $\mathrm{T}$ cell mediated since transfer of HSP60-specific T cells into naïve recipients also imparted protection against arthritis in the recipients. By analyzing the exact antigen specificity of the protective $\mathrm{T}$ cells, it was discovered that disease suppression was mediated by $\mathrm{T}$ cells that responded to a particularly conserved HSP60 sequence. This sequence was so conserved that these $\mathrm{T}$ cells cross-recognized the homologous sequence present in the mammalian HSP60 molecule. Immunization with a synthetic peptide comprising this protective $\mathrm{T}$ cell epitope induced a fully protective $\mathrm{T}$ cell response against arthritis (Anderton et al. 1995). Cytokine analyses of the protective $\mathrm{T}$ cells demonstrated their capacity to produce suppressive cytokines such as IL-10 (Prakken et al. 2001). Since then, similar protective effects have been shown for microbial HSPs, including members of the HSP70 family, in various experimental models of autoimmunity (summarized in (van Eden et al. 2005).

A recent study by Borges et al. further demonstrated the immunosuppressive potential of mycobacterial HSP70 in two allograft survival models, an allogeneic melanoma and a regular allogeneic skin graft. Very interestingly, rejection was inhibited by HSP70 incubation of the melanoma cells or the skin prior to grafting. Concurrent injection of an antiCD25 antibody removed Treg cells and fully abolished the rejection inhibitory effect (Borges et al. 2010). Altogether, astonishing findings for a molecule derived from a microbe - mycobacterium - which is known to have such strong immune-potentiating effects!

In some studies, immunizations with mammalian HSP have also been shown to inhibit disease. This was done in arthritis for HSP60 (Paul et al. 2000) and HSP70 (Chandawarkar et al. 2004; Corrigall et al. 2001; Wendling et al. 2000) and in diabetes with an HSP60-derived peptide (Bockova et al. 1997). In in vitro studies, Gp96 (glucoseregulated protein 94), a member of the HSP90 family of 
stress proteins, was seen to have no effect on bone marrowderived dendritic cells, but at a higher dose led to an increased IL-10/INF- $\gamma$ ratio in T cells. This skewing also indicated the induction of a regulatory mode in T cells and was shown to induce a state of $\mathrm{T}$ cell hyporesponsiveness and delay the rejection of cardiac allografts in rats (Mirza et al. 2006; Slack et al. 2007).

More recently, we have shown that endogenous upregulation of HSP by HSP co-inducing compounds may also lead to the induction of HSP-specific Treg cells. In the mouse model of proteoglycan-induced arthritis, we have shown that oral administration of oregano-derived carvacrol led to the upregulation of HSP70 in gut Peyer's patches and draining lymph nodes and to the suppression of disease development. Also, T cells were found to exhibit elevated HSP70-specific recall responses. Moreover, the $\mathrm{T}$ cells responding to oral carvacrol treatment were shown to be $\mathrm{CD} 4{ }^{+} \mathrm{CD} 25^{+} \mathrm{Foxp}^{+}$in the spleen and in the joint, indicating that the disease suppression was mediated by the induction of genuine Treg cells (Wieten et al. 2010). A similar effect may have occurred in the case of triptolideinduced HSP70 expression, which may have yielded the protective effect in EAE models for multiple sclerosis (van Eden 2009).

Genetic evidence for a disease suppressive role of endogenous HSP70 was obtained in a transgenic mouse model of dextran sulfate sodium-induced colitis. Reduced disease and less pro-inflammatory cytokine production were seen in HSP70-overexpressing animals. In HSF-1 null mice, the opposite phenotype was observed, as disease worsened and more pro-inflammatory cytokines were produced (Tanaka et al. 2007). A similar study showed the disease suppressive role of HSP70 in bleomycininduced pulmonary fibrosis (Tanaka et al. 2010).

Recently, Shields et al. introduced the idea of certain HSP molecules acting as "resolution-associated molecular patterns" or RAMPs. RAMPs were proposed to exert immunological activity by restoring immune homeostasis by deactivating cells of the innate immune system and by expanding regulatory cells (Shields et al. 2011). While they accept the idea that most HSP will act as DAMPs, they propose some HSP molecules (HSP10, HSP27, alpha Bcrystallin, and BiP or GRP78) to be exceptional and to act as RAMPs. In our opinion, the examples they cite have effects similar to those seen for members of major HSP families such as HSP60 and HSP70. HSP10 was formerly known as the early pregnancy factor and had an immune regulatory role in preventing of rejection of the allogeneic embryo. Since then, HSP10 was found to have immune regulatory effects in various other systems: serum levels were found to correlate with $\mathrm{T}$ cell receptor down-modulation (CD3 $\zeta$ expression), proliferation of Jurkat $\mathrm{T}$ cell lines was inhibited, and in vitro, HSP10 pretreatment inhibited LPS- stimulated TNF- $\alpha$ and IL-6 secretion by human peripheral blood mononuclear cells (Johnson et al. 2005).

Recombinant HSP27 has a tendency to induce IL-10 secretion in cultured human monocytes, and it blocks differentiation of monocytes to dendritic cells (De et al. 2000; Laudanski et al. 2007). In monocytes, the HSP70 family member BiP was found to downregulate MHC and the co-stimulatory molecule CD86. Instead, it stimulated production of anti-inflammatory cytokines IL-1 receptor antagonist, soluble TNF receptor II, and IL-10 (Corrigall et al. 2004).

Additional immunosuppressive effects of HSP have also been seen in the case of exosome-associated HSP70. Membrane-associated HSP72 obtained from tumor-derived exosomes were observed to mediate a suppressive activity in myeloid-derived suppressor cells. Possibly, this is one mechanism by which tumor immune surveillance is restrained (Chalmin et al. 2010). The possible further complexity of HSP-associated cellular export vesicles and cellular communications under stress conditions and its potential implications have already been discussed in an authoritative manner by de Maio in an earlier perspective and reflection article (De Maio 2011).

\section{HSP and immune homeostasis}

If we refute the possibility that HSP are DAMPs, and we recognize the prominent role of HSP in cognate interactions with the immune system, we are confronted with the question of what the actual immunological significance of HSP may be. The elevated levels of HSP in inflamed, traumatized, or reperfused tissues in combination with the extensive immune repertoire of cells with the capacity to recognize HSP indicate that these proteins may be biomarkers of damage, providing targets for immune mechanisms involved in restoration of tissue and immune homeostasis.

With the recent rediscovery of regulatory $\mathrm{T}$ cells (Treg), the role of the immune system in homeostasis has received renewed interest. Also the reinterpretation of self/nonself discrimination, as was revamped by the "danger" concept, seems to have boosted our appreciation of mechanisms of immune homeostasis.

Currently, there is a flurry of interest in the host-microbe interrelationships at the level of the gut microbiota. The immune system cannot tolerate becoming rampantly stimulated by foreign molecules, but has to figure out whether a certain stimulus is just microbial nonself or a signal of imminent danger. In the case of benign microbial nonself as present in our enteric microbiota, a carefully regulated response suffices or is even imperative. It is in this relationship that a major role for Treg cells is proposed. Despite many technical obstacles, it is now widely accepted 
that Treg cells do exist and can suppress immune responses in an antigen-specific manner, also in areas other than the gut. There are two functional categories of Treg cells. Natural Treg cells are represented by a specialized subset of CD $4^{+}$DC $25^{+}$Foxp $^{+}$T cells that are selected in the thymus on the basis of relatively high affinity self-recognition. The second group is inducible Treg cells. These $\mathrm{CD}^{+} \mathrm{T}$ cells, which are also mostly $\mathrm{CD} 25^{+} \mathrm{Foxp}^{+}$, are programmed in the peripheral lymphoid organs or in the tissues to adopt a regulatory status. Notably, HSPs are abundantly expressed in the thymus in the areas where positive selection of $\mathrm{T}$ cells takes place (Anderson et al. 2002). Therefore, HSPspecific natural Treg cells may be selected in the thymus, whereas HSP-specific induced Treg cells may originate from elevated HSP expression in stressed peripheral tissues.

Besides their prominent role in the maintenance of immune homeostasis in relation to symbiotic interactions with the gut microbiota, Treg cells are implicated in the anti-inflammatory responses that are seen in autoimmunity, cancer, and infection (Vignali et al. 2008). During infection, Treg cells help to resolve the pro-inflammatory response, thereby reducing bystander damage. In addition, Treg cells may be even more fundamental in the organization of the immune response. For example, it has been shown that Treg cells may function to aid in efficient cell entry into sites of infection (Lund et al. 2008).

On the basis of the findings in experimental animal models, new evidence seems to have surfaced that HSP can be antigens that stimulate the activity of Treg cells (see also previous section). For several reasons, this latter possibility may be plausible and attractive.

Every cell in the body harbors the full spectrum of HSP molecules. Under stress, many of them are upregulated, and their fragments are processed and presented by $\mathrm{MHC}$ molecules on the cell surface. HSP70 may have a preferential position here. Some HSP70 family members (Hsc70 or HSPA8 and in addition DNAJB1 and HSPC) are involved in chaperone-mediated autophagy, a process whereby during stress or nutrient deprivation cytosolic proteins are reused by cells and are routed through a subcellular compartment that intersects with the MHC class II route (Majeski and Fred Dice 2004). This means that, especially under stress, fragments of HSP70 may be loaded into MHC class II products. Herewith HSP70 epitopes are being presented in a preferential manner to $\mathrm{CD}^{+} \mathrm{T}$ cells, which includes Tregs. Based on other arguments, such as the autophagy-mediated disposition of proteins with a long half-life and MHC binding predictions, HSP70 has already been proposed as an important source of peptides to be loaded onto MHC class II molecules, also in the absence of stress (Paludan et al. 2005). A mass spectroscopy analysis of peptides eluted from $\mathrm{MHC}$ class II obtained from stressed human B cells, revealed that HSP70 (HSPA1A,
HSPA6, and HSPA8) fragments composed a major portion of the bound collection of peptides (Dengjel et al. 2005). Thus, the immune system, including Treg cells, has ample opportunity to encounter MHC-presented HSP epitopes, and this will be especially prevalent during inflammation or other stress conditions.

For Treg cell-mediated immune homeostasis this situation may be ideal. When trying to imagine how antigenspecific Treg cells could work, one has to realize that it is unlikely that effective regulation is secondary to the presence of a very small number of autoantigen-specific Treg cells present in a polyclonal population. As already pointed out by Shevach, a more likely scenario is that polyclonal Treg cells are able to exert control because they are being regularly activated through their TCR by complexes of MHC class II and ubiquitous self-peptides (Shevach 2009). If so, HSPs would provide an excellent collection of prominently expressed - certainly under stressubiquitous self antigens. This qualifies them very well as targets for $\mathrm{T}$ cell regulation.

HSPs are further implicated in many situations where host immune homeostasis is challenged. Figure 1 represents three typical scenarios: sterile tissue damage (autoimmune inflammation, reperfusion injury, heat stress), true danger imposed by pathogen invasion (infection), and commensalism/symbiosis (e.g., exposure to gut microbiota). Maintenance of tissue homeostasis is required in all these instances, and one may assume that the immune system is having a major role here. This may well include the responses of the immune system to HSP. Given the postulated capacity of HSPs to trigger Treg cells, it seems attractive to attribute, at least in part, the restoration of tissue and immune homeostasis to the activity of HSP-specific Treg cells.

\section{Extracellular versus intracellular HSP}

There exist two ways by which heat shock proteins can interact with the immune system (Fig. 2). First of all, their intracellular upregulation as a consequence of cell stress will lead to upregulated MHC presentation of HSP fragments (peptides) at the cell surface making them visible to $\mathrm{T}$ cells. Secondly, they may be translocated by yet undefined mechanisms, as complete molecules to the cell surface or to the extracellular environment. This would allow them to be encountered by NK cells, antibodies, and antigen-presenting cells. Besides active translocation, cell necrosis is probably a mechanism through which HSPs are released into the extracellular environment. It is safe to conclude that these two distinct contexts for HSP interactions with the immune system will lead to distinct immunological outcomes.

In principle, DAMP producing cell death is proposed to result mainly from necrosis. Whether cell death is immu- 
Fig. 1 The immune system will restore homeostasis when the latter is challenged by sterile damage, pathogens, or commensals. In all cases, HSPs are present and even upregulated host responses are terminated by regulation. In the host response, the HSP can be the targets for the regulation, such as for the regulation exerted by Treg cells

\section{Challengers of host \\ immune -homeostasis}

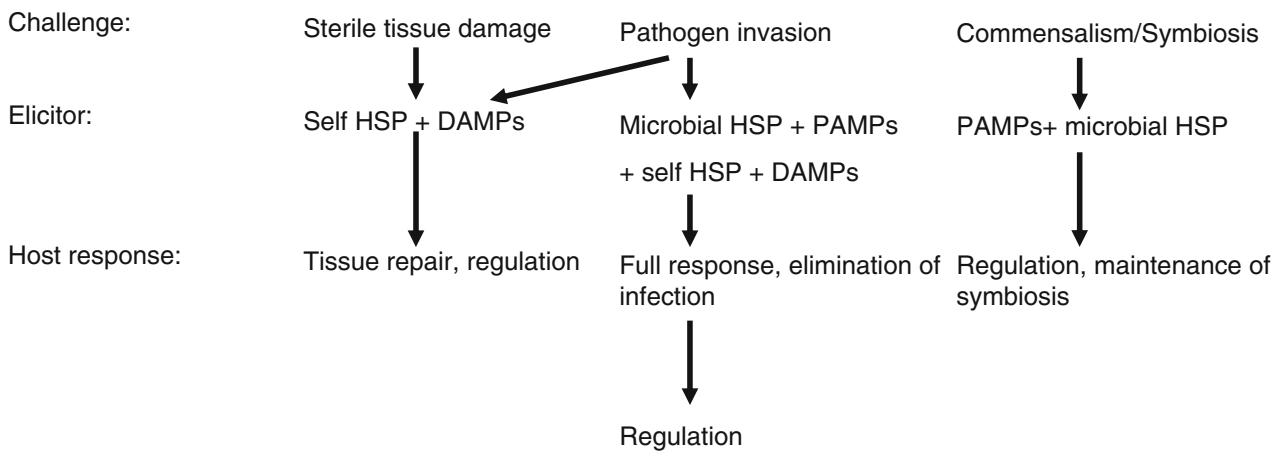

nogenic, tolerogenic, or "silent" is, these days, one of the central issues in immunology. There is ample evidence that apoptosis is non-immunogenic. However, the activation state of dying cells seems relevant (Green et al. 2009). Activated apoptotic cells have adjuvant properties and induce expression of maturation markers (CD80, CD83, and CD86) and secretion of pro-inflammatory cytokines in DCs (Johansson et al. 2007). In contrast to this, T cells that succumb to activation-induced cell death after clonal expansion promote tolerance by stimulating regulatory
$\mathrm{CD} 8^{+} \mathrm{T}$ cells (Herndon et al. 2005). Thus, timing of cell death seems important: cell death at the peak of the immune response produces immune activation, whereas cell death during a waning immune response supports regulation. Most necrotic cells are considered to produce an immune response, but also here the cell type, the history of the cell, its mode of activation, and the manner of stress imposed on the cell may determine whether or not this form of cell death is immunogenic (Green et al. 2009). In other words, as long as we do not know exactly how to correlate the
Fig. 2 Extracellular HSPs are released from necrotic cells when cells die from infection. The released HSP will be seen by receptors on antigenpresenting cells such as DC in combination with PAMPs. It is possible that HSPs do contribute to the PAMP-elicited inflammatory response, thereby enhancing collateral tissue damage. Sterile inflammation will upregulate intracellular HSP in antigen-presenting cells such as DC which leads to the triggering of regulatory $\mathrm{T}$ cells that dampen inflammation

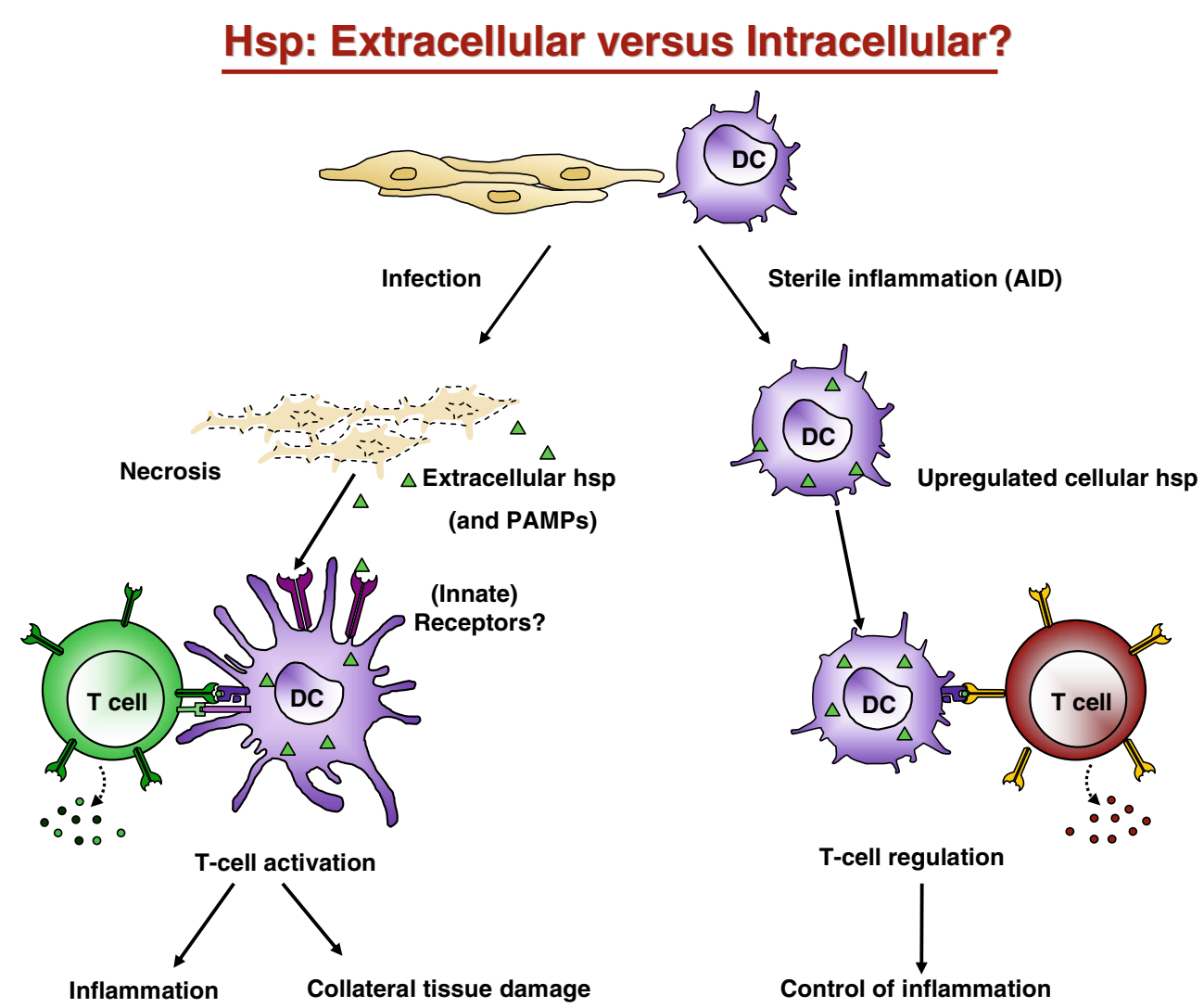


position of HSPs with the type and circumstances of cell death, it will be hard to fully grasp the immunological role of HSP in cell death.

One of the problems that is associated with the immunogenicity of cell death is that cell death due to infection needs to be immunogenic, at least to some extent. When dying cells would provide antigens, let us say HSP, that would lead to a firm tolerance or suppressive regulation, such tolerance or suppressive regulation would possibly include the microbial invader that led to cell death. This scenario is incompatible with effective antimicrobial defense. The alternative possibility is that DAMPs of dying cells would always promote immune responses. This is also problematic since this would convey the risk of autoimmunity. Again, given the complexity of cell death immunogenicity, there may not be a simple one-dimensional role in cell death for HSP.

In the case of cell death due to infection, PAMPs may have an overriding effect driving a pro-inflammatory response, at least at the start of infection. One cannot exclude that extracellular HSPs contribute a positive proinflammatory effect of PAMP-activated cells, such as activated DCs by possibly amplifying their TLR signaling. It is also possible that HSPs form complexes with PAMPs to support pro-inflammatory activity by chaperoning the PAMPs involved or by synergistic effects. A similar discussion has been active with respect to HMGB-1. It was proposed that HMGB-1 released in the presence of TLR-binding PAMPs acted to promote inflammation, whereas HMGB-1 released in an environment devoid of PAMPs promoted tissue repair (Harris and Raucci 2006). If this were the case, then it seems reasonable to assume a similar situation for HSP.

Necrosis resulting from infection will lead to a proinflammatory response based on recognition of both PAMPs/DAMPs and possibly HSPs. The ensuing elimination of the invaders would coincide with collateral damage. At this point, regulation in the form of active resolution, in part based on HSP recognizing Treg cell, would kick-in and contribute to restoration of tissue homeostasis. From another point, intracellular HSP would, besides their main task in safeguarding against intracellular protein misfolding under stress, find its way to the cell surface in the context of MHC molecules and trigger a presumably regulatory response at the level of $\mathrm{T}$ cells.

In addition, there may be still be the somewhat theoretical issue of active concentrations of HSP. At low, more or less constitutive concentrations, HSP may help to maintain immune homeostasis by promoting Treg cell activities. However, it is theoretically possible that relatively high concentrations of HSP that are liberated at sites of tissue damage or infection cause a loss of regulatory capacity and contribute to pro-inflammatory responses.
This would imply that when cellular stress decreases, resolution would set in and Treg cells would become prominent responders when local HSP concentrations fall (Quintana and Cohen 2011).

Irrespective of possible pro-inflammatory effects of supra-constitutive concentrations of HSP, under physiological conditions, a dampening effect on the immune system would prevail. Mounting experimental findings seem to support the latter supposition. HSP can therefore be called DAMPERs rather than DAMPs. This may be very much in line with the recent successful clinical interventions in autoimmune inflammatory diseases based on the administration of HSP peptides (Albani et al. 2011; Fischer et al. 2010; van Eden et al. 2010).

Acknowledgments We would like to thank Dr. Ineke den Braber and Dr. Karen Malone for critical reading and giving suggestions for improving the manuscript. We thank the EU-funded Tolerage project (Health-F4-2008), the IOP Genomics (SenterNovem), and the Dutch Reumafonds for financing part of our work.

Open Access This article is distributed under the terms of the Creative Commons Attribution Noncommercial License which permits any noncommercial use, distribution, and reproduction in any medium, provided the original author(s) and source are credited.

\section{References}

Abulafia-Lapid R, Gillis D, Yosef O, Atlan H, Cohen IR (2003) T cells and autoantibodies to human HSP70 in type 1 diabetes in children. J Autoimmun 20:313-321

Aderem A (2003) Phagocytosis and the inflammatory response. J Infect Dis 187(Suppl 2):S340-5

Albani S, Koffeman EC, Prakken B (2011) Induction of immune tolerance in the treatment of rheumatoid arthritis. Nat Rev Rheumatol 7:272-281

Anderson MS, Venanzi ES, Klein L, Chen Z, Berzins SP, Turley SJ, von Boehmer H, Bronson R, Dierich A, Benoist C, Mathis D (2002) Projection of an immunological self shadow within the thymus by the aire protein. Science $298: 1395-1401$

Anderton SM, van der Zee R, Prakken B, Noordzij A, van Eden W (1995) Activation of $\mathrm{T}$ cells recognizing self $60-\mathrm{kD}$ heat shock protein can protect against experimental arthritis. J Exp Med 181:943-952

Arnold-Schild D, Hanau D, Spehner D, Schmid C, Rammensee HG, de la Salle H, Schild H (1999) Cutting edge: receptor-mediated endocytosis of heat shock proteins by professional antigenpresenting cells. J Immunol 162:3757-3760

Bausinger H, Lipsker D, Ziylan U, Manie S, Briand JP, Cazenave JP, Muller S, Haeuw JF, Ravanat C, de la Salle H, Hanau D (2002) Endotoxin-free heat-shock protein 70 fails to induce APC activation. Eur J Immunol 32:3708-3713

Bendz H, Marincek BC, Momburg F, Ellwart JW, Issels RD, Nelson PJ, Noessner E (2008) Calcium signaling in dendritic cells by human or mycobacterial Hsp70 is caused by contamination and is not required for Hsp70-mediated enhancement of crosspresentation. J Biol Chem 283:26477-26483

Bianchi ME (2007) DAMPs, PAMPs and alarmins: all we need to know about danger. J Leukoc Biol 81:1-5 
Binder RJ (2009) Hsp receptors: the cases of identity and mistaken identity. Curr Opin Mol Ther 11:62-71

Bockova J, Elias D, Cohen IR (1997) Treatment of NOD diabetes with a novel peptide of the hsp60 molecule induces Th2-type antibodies. J Autoimmun 10:323-329

Borges TJ, Porto BN, Teixeira CA, Rodrigues M, Machado FD, Ornaghi AP, de Souza AP, Maito F, Pavanelli WR, Silva JS, Bonorino C (2010) Prolonged survival of allografts induced by mycobacterial Hsp70 is dependent on CD4+CD25+ regulatory $\mathrm{T}$ cells. PLoS One 5:e14264

Broere F, van der Zee R, van Eden W (2011) Heat shock proteins are no DAMPs, rather 'DAMPERs'. Nat Rev Immunol 11:565-c1

Calderwood SK, Mambula SS, Gray PJ Jr, Theriault JR (2007) Extracellular heat shock proteins in cell signaling. FEBS Lett 581:3689-3694

Caramalho I, Lopes-Carvalho T, Ostler D, Zelenay S, Haury M, Demengeot J (2003) Regulatory T cells selectively express tolllike receptors and are activated by lipopolysaccharide. J Exp Med 197:403-411

Chalmin F, Ladoire S, Mignot G, Vincent J, Bruchard M, Remy-Martin JP, Boireau W, Rouleau A, Simon B, Lanneau D, De Thonel A, Multhoff G, Hamman A, Martin F, Chauffert B, Solary E, Zitvogel L, Garrido C, Ryffel B, Borg C, Apetoh L, Rebe C, Ghiringhelli F (2010) Membrane-associated Hsp72 from tumor-derived exosomes mediates STAT3-dependent immunosuppressive function of mouse and human myeloid-derived suppressor cells. J Clin Invest 120:457471

Chandawarkar RY, Wagh MS, Kovalchin JT, Srivastava P (2004) Immune modulation with high-dose heat-shock protein gp96: therapy of murine autoimmune diabetes and encephalomyelitis. Int Immunol 16:615-624

Chen GY, Nunez G (2010) Sterile inflammation: sensing and reacting to damage. Nat Rev Immunol 10:826-837

Cho BK, Palliser D, Guillen E, Wisniewski J, Young RA, Chen J, Eisen HN (2000) A proposed mechanism for the induction of cytotoxic $\mathrm{T}$ lymphocyte production by heat shock fusion proteins. Immunity 12:263-272

Cohen IR (2007) Biomarkers, self-antigens and the immunological homunculus. J Autoimmun 29:246-249

Cohen-Sfady M, Nussbaum G, Pevsner-Fischer M, Mor F, Carmi P, Zanin-Zhorov A, Lider O, Cohen IR (2005) Heat shock protein 60 activates $\mathrm{B}$ cells via the TLR4-MyD88 pathway. J Immunol 175:3594-3602

Conroy H, Marshall NA, Mills KH (2008) TLR ligand suppression or enhancement of Treg cells? A double-edged sword in immunity to tumours. Oncogene 27:168-180

Corrigall VM, Bodman-Smith MD, Fife MS, Canas B, Myers LK, Wooley P, Soh C, Staines NA, Pappin DJ, Berlo SE, van Eden W, van Der Zee R, Lanchbury JS, Panayi GS (2001) The human endoplasmic reticulum molecular chaperone $\mathrm{BiP}$ is an autoantigen for rheumatoid arthritis and prevents the induction of experimental arthritis. J Immunol 166:1492-1498

Corrigall VM, Bodman-Smith MD, Brunst M, Cornell H, Panayi GS (2004) Inhibition of antigen-presenting cell function and stimulation of human peripheral blood mononuclear cells to express an antiinflammatory cytokine profile by the stress protein BiP: relevance to the treatment of inflammatory arthritis. Arthritis Rheum 50:1164-1171

de Graeff-Meeder ER, van Eden W, Rijkers GT, Prakken BJ, Kuis W, Voorhorst-Ogink MM, van der Zee R, Schuurman HJ, Helders PJ, Zegers BJ (1995) Juvenile chronic arthritis: T cell reactivity to human HSP60 in patients with a favorable course of arthritis. J Clin Invest 95:934-940

de Kleer IM, Kamphuis SM, Rijkers GT, Scholtens L, Gordon G, De Jager W, Hafner R, van de Zee R, van Eden W, Kuis W, Prakken BJ (2003) The spontaneous remission of juvenile idiopathic arthritis is characterized by $\mathrm{CD} 30+\mathrm{T}$ cells directed to human heat-shock protein 60 capable of producing the regulatory cytokine interleukin-10. Arthritis Rheum 48:2001-2010

De Maio A (2011) Extracellular heat shock proteins, cellular export vesicles, and the Stress Observation System: a form of communication during injury, infection, and cell damage. It is never known how far a controversial finding will go! Dedicated to Ferruccio Ritossa. Cell Stress Chaperones 16:235-249

De AK, Kodys KM, Yeh BS, Miller-Graziano C (2000) Exaggerated human monocyte IL-10 concomitant to minimal TNF-alpha induction by heat-shock protein 27 (Hsp27) suggests Hsp27 is primarily an antiinflammatory stimulus. J Immunol 165:39513958

Dengjel J, Schoor O, Fischer R, Reich M, Kraus M, Muller M, Kreymborg K, Altenberend F, Brandenburg J, Kalbacher $\mathrm{H}$, Brock R, Driessen C, Rammensee HG, Stevanovic S (2005) Autophagy promotes MHC class II presentation of peptides from intracellular source proteins. Proc Natl Acad Sci U S A 102:7922-7927

Durai M, Gupta RS, Moudgil KD (2004) The T cells specific for the carboxyl-terminal determinants of self (rat) heat-shock protein 65 escape tolerance induction and are involved in regulation of autoimmune arthritis. J Immunol 172:2795-2802

Fischer B, Elias D, Bretzel RG, Linn T (2010) Immunomodulation with heat shock protein DiaPep277 to preserve beta cell function in type 1 diabetes - an update. Expert Opin Biol Ther 10:265272

Floto RA, MacAry PA, Boname JM, Mien TS, Kampmann B, Hair JR, Huey OS, Houben EN, Pieters J, Day C, Oehlmann W, Singh M, Smith KG, Lehner PJ (2006) Dendritic cell stimulation by mycobacterial Hsp70 is mediated through CCR5. Science 314:454-458

Fuchs EJ, Matzinger P (1996) Is cancer dangerous to the immune system? Semin Immunol 8:271-280

Green DR, Ferguson T, Zitvogel L, Kroemer G (2009) Immunogenic and tolerogenic cell death. Nat Rev Immunol 9:353-363

Harris HE, Raucci A (2006) Alarmin(g) news about danger: workshop on innate danger signals and HMGB1. EMBO Rep 7:774-778

Henderson B, Calderwood SK, Coates AR, Cohen I, van Eden W, Lehner T, Pockley AG (2010) Caught with their PAMPs down? The extracellular signalling actions of molecular chaperones are not due to microbial contaminants. Cell Stress Chaperones 15:123-141

Herndon JM, Stuart PM, Ferguson TA (2005) Peripheral deletion of antigen-specific $\mathrm{T}$ cells leads to long-term tolerance mediated by CD8+ cytotoxic cells. J Immunol 174:4098-4104

Johansson U, Walther-Jallow L, Smed-Sorensen A, Spetz AL (2007) Triggering of dendritic cell responses after exposure to activated, but not resting, apoptotic PBMCs. J Immunol 179:1711-1720

Johnson BJ, Le TT, Dobbin CA, Banovic T, Howard CB, Flores Fde M, Vanags D, Naylor DJ, Hill GR, Suhrbier A (2005) Heat shock protein 10 inhibits lipopolysaccharide-induced inflammatory mediator production. J Biol Chem 280:4037-4047

Kaufmann SH, Vath U, Thole JE, Van Embden JD, Emmrich F (1987) Enumeration of T cells reactive with Mycobacterium tuberculosis organisms and specific for the recombinant mycobacterial 64$\mathrm{kDa}$ protein. Eur J Immunol 17:351-357

Kono H, Rock KL (2008) How dying cells alert the immune system to danger. Nat Rev Immunol 8:279-289

Land WG (2005) Injury to allografts: innate immune pathways to acute and chronic rejection. Saudi J Kidney Dis Transpl 16:520 539

Laudanski K, De A, Miller-Graziano C (2007) Exogenous heat shock protein 27 uniquely blocks differentiation of monocytes to dendritic cells. Eur J Immunol 37:2812-2824 
Luan ZG, Zhang H, Yang PT, Ma XC, Zhang C, Guo RX (2010) HMGB1 activates nuclear factor-kappaB signaling by RAGE and increases the production of TNF-alpha in human umbilical vein endothelial cells. Immunobiology 215:956-962

Lund JM, Hsing L, Pham TT, Rudensky AY (2008) Coordination of early protective immunity to viral infection by regulatory $\mathrm{T}$ cells. Science 320:1220-1224

Majeski AE, Fred Dice J (2004) Mechanisms of chaperone-mediated autophagy. Int J Biochem Cell Biol 36:2435-2444

Martin-Murphy BV, Holt MP, Ju C (2010) The role of damage associated molecular pattern molecules in acetaminopheninduced liver injury in mice. Toxicol Lett 192:387-394

Mirza S, Muthana M, Fairburn B, Slack LK, Hopkinson K, Pockley AG (2006) The stress protein gp96 is not an activator of resting rat bone marrow-derived dendritic cells, but is a costimulator and activator of CD3 + T cells. Cell Stress Chaperones 11:364-378

Motta A, Schmitz C, Rodrigues L, Ribeiro F, Teixeira C, Detanico T, Bonan C, Zwickey H, Bonorino C (2007) Mycobacterium tuberculosis heat-shock protein 70 impairs maturation of dendritic cells from bone marrow precursors, induces interleukin-10 production and inhibits T-cell proliferation in vitro. Immunology 121:462-472

Moudgil KD, Chang TT, Eradat H, Chen AM, Gupta RS, Brahn E, Sercarz EE (1997) Diversification of T cell responses to carboxyterminal determinants within the $65-\mathrm{kD}$ heat-shock protein is involved in regulation of autoimmune arthritis. J Exp Med $185: 1307-1316$

Multhoff G (2007) Heat shock protein 70 (Hsp70): membrane location, export and immunological relevance. Methods 43:229-237

Paludan C, Schmid D, Landthaler M, Vockerodt M, Kube D, Tuschl T, Munz C (2005) Endogenous MHC class II processing of a viral nuclear antigen after autophagy. Science 307:593-596

Paul AG, van Kooten PJ, van Eden W, van der Zee R (2000) Highly autoproliferative $\mathrm{T}$ cells specific for $60-\mathrm{kDa}$ heat shock protein produce IL-4/IL-10 and IFN-gamma and are protective in adjuvant arthritis. J Immunol 165:7270-7277

Pisetsky DS, Erlandsson-Harris H, Andersson U (2008) High-mobility group box protein 1 (HMGB1): an alarmin mediating the pathogenesis of rheumatic disease. Arthritis Res Ther 10:209

Pockley AG, Multhoff G (2008) Cell stress proteins in extracellular fluids: friend or foe? Novartis Found Symp 291:86-95, discussion 96-100, 137-40

Prakken AB, van Eden W, Rijkers GT, Kuis W, Toebes EA, de Graeff-Meeder ER, van der Zee R, Zegers BJ (1996) Autoreactivity to human heat-shock protein 60 predicts disease remission in oligoarticular juvenile rheumatoid arthritis. Arthritis Rheum 39:1826-1832

Prakken BJ, Wendling U, van der Zee R, Rutten VP, Kuis W, van Eden W (2001) Induction of IL-10 and inhibition of experimental arthritis are specific features of microbial heat shock proteins that are absent for other evolutionarily conserved immunodominant proteins. J Immunol 167:4147-4153

Quintana FJ, Cohen IR (2011) The HSP60 immune system network. Trends Immunol 32:89-95

Quintana FJ, Basso AS, Iglesias AH, Korn T, Farez MF, Bettelli E, Caccamo M, Oukka M, Weiner HL (2008) Control of T(reg) and $\mathrm{T}(\mathrm{H}) 17$ cell differentiation by the aryl hydrocarbon receptor. Nature 453:65-71

Rock KL, Shen L (2005) Cross-presentation: underlying mechanisms and role in immune surveillance. Immunol Rev 207:166-183

Rouhiainen A, Tumova S, Valmu L, Kalkkinen N, Rauvala H (2007) Pivotal advance: analysis of proinflammatory activity of highly purified eukaryotic recombinant HMGB1 (amphoterin). J Leukoc Biol 81:49-58

Round JL, Mazmanian SK (2010) Inducible Foxp3+ regulatory T-cell development by a commensal bacterium of the intestinal microbiota. Proc Natl Acad Sci U S A 107:12204-12209
Seong SY, Matzinger P (2004) Hydrophobicity: an ancient damageassociated molecular pattern that initiates innate immune responses. Nat Rev Immunol 4:469-478

Shevach EM (2009) Mechanisms of foxp3+ T regulatory cellmediated suppression. Immunity 30:636-645

Shields AM, Panayi GS, Corrigall VM (2011) Resolution-associated molecular patterns (RAMP): RAMParts defending immunological homeostasis? Clin Exp Immunol 165:292-300

Slack LK, Muthana M, Hopkinson K, Suvarna SK, Espigares E, Mirza S, Fairburn B, Pockley AG (2007) Administration of the stress protein gp96 prolongs rat cardiac allograft survival, modifies rejection-associated inflammatory events, and induces a state of peripheral T-cell hyporesponsiveness. Cell Stress Chaperones 12:71-82

Sutmuller RP, den Brok MH, Kramer M, Bennink EJ, Toonen LW, Kullberg BJ, Joosten LA, Akira S, Netea MG, Adema GJ (2006) Toll-like receptor 2 controls expansion and function of regulatory T cells. J Clin Invest 116:485-494

Tanaka K, Namba T, Arai Y, Fujimoto M, Adachi H, Sobue G, Takeuchi K, Nakai A, Mizushima T (2007) Genetic evidence for a protective role for heat shock factor 1 and heat shock protein 70 against colitis. J Biol Chem 282:23240-23252

Tanaka K, Tanaka Y, Namba T, Azuma A, Mizushima T (2010) Heat shock protein 70 protects against bleomycin-induced pulmonary fibrosis in mice. Biochem Pharmacol 80:920-931

Thole JE, Dauwerse HG, Das PK, Groothuis DG, Schouls LM, van Embden JD (1985) Cloning of Mycobacterium bovis BCG DNA and expression of antigens in Escherichia coli. Infect Immun 50:800-806

Thole JE, Hindersson P, de Bruyn J, Cremers F, van der Zee J, de Cock H, Tommassen J, van Eden W, van Embden JD (1988) Antigenic relatedness of a strongly immunogenic $65 \mathrm{kDA}$ mycobacterial protein antigen with a similarly sized ubiquitous bacterial common antigen. Microb Pathog 4:71-83

Tsan MF, Gao B (2009) Heat shock proteins and immune system. J Leukoc Biol 85:905-910

Ulmansky R, Cohen CJ, Szafer F, Moallem E, Fridlender ZG, Kashi Y, Naparstek Y (2002) Resistance to adjuvant arthritis is due to protective antibodies against heat shock protein surface epitopes and the induction of IL-10 secretion. J Immunol 168:6463-6469

Vabulas RM, Ahmad-Nejad P, da Costa C, Miethke T, Kirschning CJ, Hacker H, Wagner H (2001) Endocytosed HSP60s use toll-like receptor 2 (TLR2) and TLR4 to activate the toll/interleukin-1 receptor signaling pathway in innate immune cells. J Biol Chem 276:31332-31339

van Eden W (2009) Protective and therapeutic effect of triptolide in EAE explained by induction of major stress protein HSP70. J Neuroimmunol 217:10-11

van Eden W, Thole JE, van der Zee R, Noordzij A, van Embden JD, Hensen EJ, Cohen IR (1988) Cloning of the mycobacterial epitope recognized by $\mathrm{T}$ lymphocytes in adjuvant arthritis. Nature 331:171-173

van Eden W, van der Zee R, Prakken B (2005) Heat-shock proteins induce T-cell regulation of chronic inflammation. Nat Rev Immunol 5:318-330

van Eden W, Lisse J, Prakken B, Albani S (2010) Biologics and postbiologics: novel immunotherapeutics for the induction and maintenance of remission. Drug Discov Today 15:71-77

Vignali DA, Collison LW, Workman CJ (2008) How regulatory T cells work. Nat Rev Immunol 8:523-532

Wallin RP, Lundqvist A, More SH, von Bonin A, Kiessling R, Ljunggren HG (2002) Heat-shock proteins as activators of the innate immune system. Trends Immunol 23:130-135

Wang XY, Facciponte J, Chen X, Subjeck JR, Repasky EA (2007) Scavenger receptor-A negatively regulates antitumor immunity. Cancer Res 67:4996-5002 
Wendling U, Paul L, van der Zee R, Prakken B, Singh M, van Eden W (2000) A conserved mycobacterial heat shock protein (hsp) 70 sequence prevents adjuvant arthritis upon nasal administration and induces IL-10-producing $\mathrm{T}$ cells that cross-react with the mammalian self-hsp70 homologue. J Immunol 164:2711-2717

Wieten L, van der Zee R, Spiering R, Wagenaar-Hilbers J, van Kooten P, Broere F, van Eden W (2010) A novel heat-shock protein coinducer boosts stress protein Hsp70 to activate T cell regulation of inflammation in autoimmune arthritis. Arthritis Rheum 62 (1026-1035):y1

Zanin-Zhorov A, Cahalon L, Tal G, Margalit R, Lider O, Cohen IR (2006) Heat shock protein 60 enhances CD4+CD25+ regulatory $\mathrm{T}$ cell function via innate TLR2 signaling. J Clin Invest 116:2022-2032

Zugel U, Kaufmann SH (1999) Immune response against heat shock proteins in infectious diseases. Immunobiology 201:22-35 